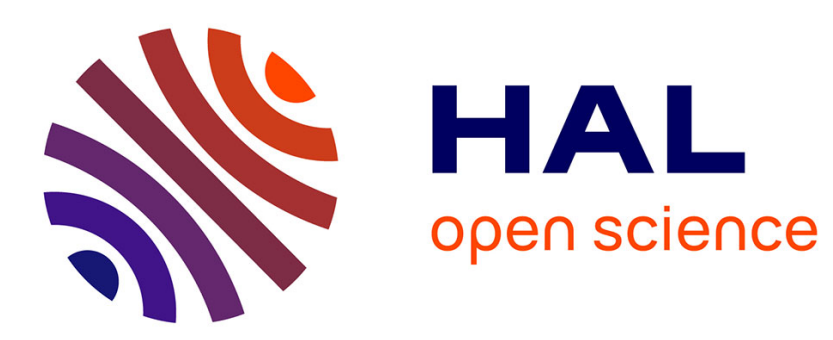

\title{
OPACITY PROJECT : RADIATIVE LIFETIMES FOR IONS IN THE Mg ISOELECTRONIC SEQUENCE
}

\author{
K. Butler, C. Mendoza, C. Zeippen
}

\section{To cite this version:}

K. Butler, C. Mendoza, C. Zeippen. OPACITY PROJECT : RADIATIVE LIFETIMES FOR IONS IN THE Mg ISOELECTRONIC SEQUENCE. Journal de Physique IV Proceedings, 1991, 01 (C1), pp.C1-135-C1-140. 10.1051/jp4:1991116 . jpa-00249754

\section{HAL Id: jpa-00249754 https://hal.science/jpa-00249754}

Submitted on 1 Jan 1991

HAL is a multi-disciplinary open access archive for the deposit and dissemination of scientific research documents, whether they are published or not. The documents may come from teaching and research institutions in France or abroad, or from public or private research centers.
L'archive ouverte pluridisciplinaire HAL, est destinée au dépôt et à la diffusion de documents scientifiques de niveau recherche, publiés ou non, émanant des établissements d'enseignement et de recherche français ou étrangers, des laboratoires publics ou privés. 


\title{
OPACITY PROJECT : RADIATIVE LIFETIMES FOR IONS IN THE Mg ISOELECTRONIC SEQUENCE
}

\author{
K. BUTLER, C. MENDOZA* and C.J. ZEIPPEN* * \\ Institut für Astronomie und Astrophysik der Universität München, D-8000 \\ München 80, Germany \\ * IBM Venezuela Scientific Center, PO. Box 64778, Caracas 1060A, \\ Venezuela \\ * Observatoire de Paris, UPR 261 du CNRS et DAMAp, F-92190 Meudon, \\ France
}

\begin{abstract}
RESUME - L'utilité de l'ensemble des forces d'oscillateur du Projet Opacity en vue du calcul de temps de vie radiatifs est examinée dans le cas des ions de la séquence isoélectronique de Mg. On discute brièrement les effets intéressants concernant les tendances spectroscopiques et isoélectroniques. L'accord entre les présents temps de vie et ceux calculés précédemment à l'aide des meilleures méthodes disponibles est très bon, mais la comparaison arec un vaste ensemble de données experimentales est moins satisfaisante. Nous concluons que le présent ensemble de données est d'une précision statistique plus grande que les valeurs mesurées.

ABSTRACT - The usability of the Opacity Project f-value dataset for the calculation of radiative lifetimes is examined in connection with ions in the $\mathrm{Mg}$ isoelectronic sequence. Interesting effects regarding spectroscopic and isoelectronic trends are briefly discussed. The agreement of the present lifetimes with those previously calculated by state-of-the-art methods is very good, but the comparison with ample experimental data is patchy. We conclude that the present dataset is of higher statistical accuracy than the measured values.
\end{abstract}

\section{1 - INTRODUCTION}

The Opacity Project $/ 1 /$ is concerned with the computation of the radiative atomic data required to estimate stellar envelope opacities. For the astrophysically abundant ions, accurate f-values are calculated for all optically allowed transitions involving bound states with effective quantum numbers $\nu \leq 10$. For this task the R-matrix method $/ 2 /$ as applied within the electron-ion close-coupling formalism, has been extended to handle efficiently the calculation of bound states and radiative data for both bound-bound and bound-free transitions $/ 3 /$. An in ruvative feature of the new approach is that initial bound-state energy estimates are no longer necessary as input; in contrast, previous numerical packages based on the close-coupling method (see, for instance, $/ 4 /$ ) required an initial estimate for the bound-state energy which usually was taken to be the spectroscopic value. As a result, eigenralues and eigenfunctions for bound states that have not been measured can now be computed. The computed energies and $\mathrm{f}$-values are stored in files which are referred to respectively as the elev and fvalue datasets, and the structure of the latter allows to estimate radiative lifetimes for all the bound states including most, if not all, the decay channels.

In the present report we discuss the usability of the fvalue dataset in the calculation of radiative lifetimes in the context of the $\mathrm{Mg}$ isoelectronic sequence. In contrast with other third-row sequences, the Mg-like ions have been extensively studied both theoretically and experimentally; this presents a unique opportunity for comparison.

\section{2 - RADIATIVE LIFETIMES}

The radiative lifetime of a state $j$ is defined as

$$
\tau_{j}=\frac{1}{\sum_{i} A_{j i}}
$$

where $A_{j i}$ is the spontaneous transition probability (in units $s^{-1}$ ) corresponding to the $j \rightarrow i$ radiative decay channel. $A_{j i}$ can be expressed in terms of the absorption oscillator strength $f_{i j}$ by

$$
A_{j i}=\frac{6.670 \times 10^{15}}{\lambda^{2}} \frac{g_{i}}{g_{j}} f_{i j}
$$

where $g_{j}$ and $g_{i}$ are the statistical weights of the upper and lower states respectively, and the wavelength $\lambda$ for Article published online by EDP Sciences and available at http://dx.doi.org/10.1051/jp4:1991116 


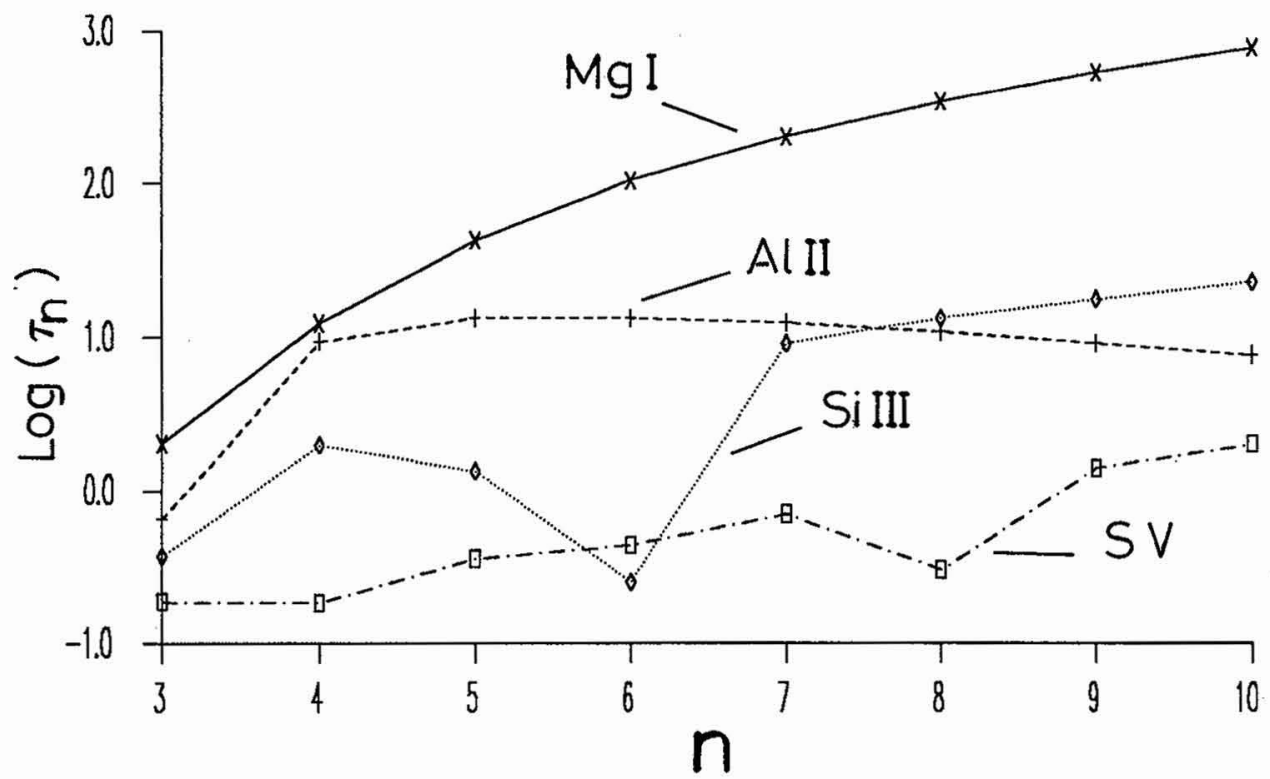

Fig. 1 - Radiative lifetimes for the $3 s n p{ }^{1} P^{0}$ singly excited states plotted as a function of $n$. Solid curve: $\mathrm{Mg}$ I. Dashed curve: Al II. Dotted curve: Si III. Dot-dashed curve: S V. The radiative lifetimes are in ns.

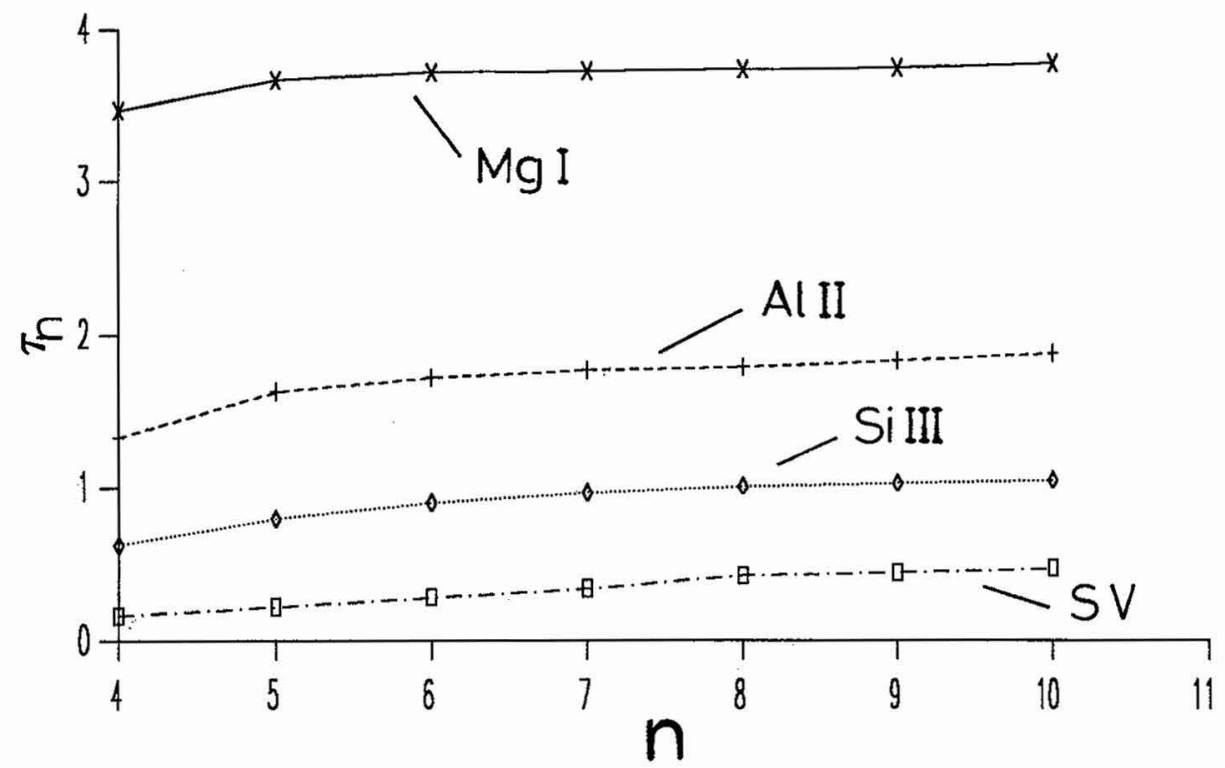

Fig. 2 - Radiative lifetimes for the $3 p n p{ }^{1} P$ doubly excited states plotted as a function of $n$. Solid curve: Mg I. Dashed curve: Al II. Dotted curve: Si III. Dot-dashed curve: S V. The radiative lifetimes are in ns.

the transition is given in $\AA$. The numerical approach to calculate bound states and $f$-values within the $R$-matrix method is summarised by Berrington et al $/ 3 /$. In the Opacity Project only the astrophysically abundant ions of the Mg isoelectronic sequence are considered, namely $\mathrm{Mg}$ I, Al II, Si III, S V, Ar VII, Ca. IX and Fe XV. The adopted target representations will be discussed elsewhere, but, briefly, all the states of the $\mathrm{Na}$-like targets with $n \leq 4$ are taken into account except for $\mathrm{Mg}$ II where the 5 s state is also included. LS-coupling is assumed throughout and core polarisation is neglected. Eigenenergies are calculated for series of bound states (singlets and triplets) of the target + e system with active-electron orbital angular momentum $l \leq 4$, total orbital angular momentum $L \leq 4$ and effective quantum number $\nu \leq 10$. This gives rise to a total of 1247 bound states and 17031 optically allowed transitions for the ions listed above; the volume of these new datasets surpass previous experimental and theoretical estimates by orders of magnitude. Furthermore, Butler et al /5/ have carried out useful statistical comparisons with spectroscopic multiplet energies and f-values calculated by other elaborate 


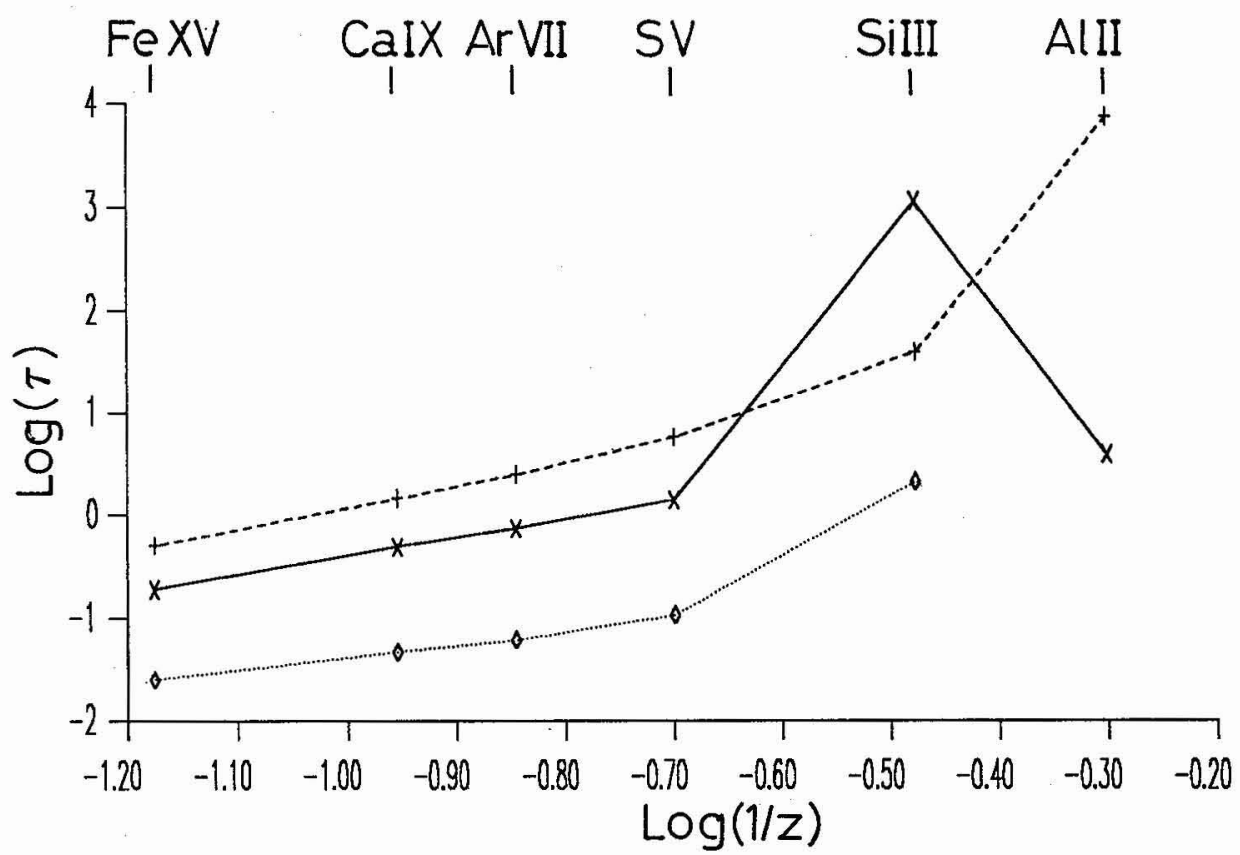

Fig. 3 - Isolectronic trends of the radiative lifetimes of the states: $3 p 3 d{ }^{3} F^{0}$ (solid curve), $3 p^{2}{ }^{1} D$ (dashed curre) and $3 p 3 d^{1} P^{0}$ (dotted curve). The radiative lifetimes are in ns.

numerical methods that indicate that the present datasets are of high statistical accuracy.

For the present report radiative lifetimes are calculated from the fvalue files using the length values and calculated wavelengths. No further refinements are performed. With the resulting lifetime values one can carry out studies of both spectroscopic series and isoelectronic trends. For instance, in Fig. 1 the lifetimes for the $3 s n{ }^{1} P^{0}$ singly excited states in Mg I, Al II, Si III and S V are plotted as a function of $n$. For these states $\tau_{n}$ increases approximately as $n^{3}$, but, as $Z$ increases, the effect of series perturbers can lead to significant departures. In contrast, the lifetimes for the $3 p n p{ }^{1} P$ doubly excited states are found to be almost independent of $n$ (see Fig. 2). This effect is caused by the complete dominance of the decay channel

$$
3 p n p^{1} P \rightarrow 3 s n p^{1} P^{0}+\gamma
$$

that corresponds to a "photo-decay of the core"; that is, the lifetimes of such states are almost equal (particularly as $n$ increases) to the lifetime of the corresponding $3 p^{2} P^{0} \mathrm{Na}$-like core state. It may be regarded as the reverse process to that that gives rise to the PEC ("photo-excitation of the core") resonances discussed by Yu Yan and Seaton $/ 6 /$.

Isoelectronic studies may be performed even though only the astrophysically abundant ions are considered. For $n=3$ states interesting trends are found for the $3 p 3 d^{1} P^{0}, 3 p 3 d^{3} F^{0}$ and $3 p^{2}{ }^{1} D$ states as shown in Fig. 3 . The first two states have electronic configurations which are usually referred to as "plunging configurations". For $\mathrm{MIg}$ I, and in some cases $\mathrm{Al} \mathrm{II}$, these doubly excited states lie above the ionisation limit giving rise to resonances, but as $Z$ increases they move down into the bound spectrum where they can perturb Rydberg states. Mixing is usually small unless the two interacting states are very close together, when extensive cancellation in the f-value may occur leading to large lifetimes. Such is the case of the $3 p 3 d^{1} P^{0}$ and $3 p 3 d^{3} F^{0}$ states of Si III which mix strongly with the $3 s 6 p^{1} p^{0}$ and $3 s 4 f^{3} F^{0}$ states respectively. The situation with the $3 p^{2}{ }^{1} D$ state is somewhat different; in agreement with previous work (see, for example, $/ 7,8 /$ ), this state is not found as a well defined state in $\mathrm{Mg} I$ and it appears as a very long-lived state below the $3 s 3 d^{1} \mathrm{D}$ in $\mathrm{Al}$ II. Cancellation in the contributions to the lifetime of the $3 p^{2}{ }^{1} D$ state due to the long-range mixing with the $3 s 3 d^{1} D$ state remains strong even as $Z$ increases.

In Table 1 we compare present lifetimes with measurements and other theoretical results. This compilation, by no means exhaustive, gives an idea of the amount of work dedicated to the radiative properties of Mg-like ions. The agreement with the lifetimes calculated by Moccia and Spizzo $/ 9 /$ for 25 states of $\mathrm{Mg}$ I using an $L^{2}$ technique is well within $10 \%$ except for 3 states $\left(3 s 4 p^{1} P^{0}, 3 s 5 p^{1} P^{0}\right.$ and $\left.3 s 3 d^{1} D\right)$ where it is around $15 \%$. Similarly the differences with the lifetimes calculated by the Multiconfiguration Hartree-Fock method of Froese 
Fischer and Godefroid /8/ for 57 singlet states of the $\mathrm{Mg}$-like ions considered here are not larger than $20 \%$, if one excludes the long-lived $3 p^{2}{ }^{1} D$ state of Al II and the strongly mixed $3 p 3 d^{1} P^{0}$ and $3 s 6 p^{1} P^{0}$ states of Si III. On the other hand, the agreement between theory and the extensive experimental data is varied and in some cases large differences are observed.

In our opinion, the lifetimes calculated in the present work are in general accurate to within $20 \%$ except for a few specific states where strong mixing leads to numerical difficulties. However, the role played by relativistic corrections in the higher members of the isoelectronic sequence should be investigated before this ranking could be asserted. We do not expect present results to change dramatically with further theoretical refinements, and the large differences found with several measurements are mostly due to experimental problems.

A list of lifetimes for Mg-like ions calculated within the Opacity Project can be obtained from C. Nendoza upon request.

\section{REFERENCES}

/1/ Seaton, M.J., J. Phys. B 20 (1987) 6363.

/2/ Burke, P.G., Hibbert A. and Robb, W.D., J. Phys. B 4 (1971) 153.

/3/ Berrington, K.A., Burke, P.G., Butler, K., Seaton, M.J., Storey, P.J., Taylor, K.T. and Yu Yan, J. Phys. B 20 (1987) 6379.

/4/ Crees, M.A., Seaton, M.J. and Wilson, P.M.H., Comput. Phys. Commun. 15 (1978) 23.

15/ Butler, K., Mendoza, C. and Zeippen, C.J., Proceedings of the Colloqium on Atomic Spectra and Oscillator Strengths for Astrophysics and Fusion Research, Hansen, J.E. (ed), Royal Dutch Academy of Sciences, Amsterdam, in press.

16/ Yu Yan and Seaton, M.J., J. Phys. B 20 (1987) 6409.

17/ Lu, K.T., J. Opt. Soc. Am. 64 (1974) 706.

18/ Froese Fischer, C. and Godefroid, M., Nucl. Instr. Meth. 202 (1982) 307.

19/ Moccia R. and Spizzo, P., J. Phys. B 21 (1988) 1133.

/10/ Lurio, A., Phys. Rev. 136 (1964) A376.

/11/ Smith, W.W. and Gallagher, A., Phys. Rev. 145 (1964) A26.

112/ Swagel, M.W. and Lurio, A.L., Phys. Rev. 169 . (1968) 114.

/13/ Andersen, T., Jessen, K.A. and Sorensen, G., J. Opt. Soc. Am. 59 (1969) 1197.

114/ Andersen, T., Désesquelles, J., Jessen, K.A. and Sørensen, G., J. Quant. Spec. Radiat. Transfer 10 (1970) 1143.

/15/ Berry, H.G., Bromander, J. and Buchta, R., Phys. Scr. 1 (1970) 181.

116/ Andersen, T., Roberts, J.R. and Sørensen, G., Phys. Scr. 4 (1971) 52.

17/ Berry, H.G., Bromander, J., Curtis, L.J. and Buchta, R., Phys. Scr. 3 (1971) 129.

/18/ Schaefer, A.R., Astrophys. J. 163 (1971) 411.

/19/ Smith, W.H. and Liszt, H.S., J. Opt. Soc. Am. 61 (1971) 938.

/20/ Andersen, T., Mølhave, L. and Sørensen, G., Astrophys. J. 178 (1972) 577.

/21/ Livingston, A.E., Irwin, D.J.G. and Pinnington, E.H.J., J. Opt. Soc. Am. 62 (1972) 1303.

/22/ Hentschel, W.R., Göbel, L.H. and Oppen, G.V., Astron. Astrophys. 29 (1973) 415.

/23/ Irwin, D.J.G., Livingston, A.E. and Kernahan, J.A., Nucl. Instr. Meth. 110 (1973) 111.

/24/ Lundin, L., Engman, B., Hilke, J. and Martinson, I., Phys. Scr. 8 (1973) 274.

/25/ Berry, H.G. and Batson, C.H., in Beam-Foil Spectroscopy, Vol. 1, Atomic Structure and Lifetimes, Sellin, I.A. and Pegg, D.J. (eds.), Plenum Press, New York (1976) 367.

/26/ Head, M.E.M., Head, C.E. and Lawrence, J.N., in Beam-Foil Spectroscopy, Vol. 1, Atomic Structure and Lifetimes, Sellin, I.A. and Pegg, D.J. (eds.), Plenum Press, New York (1976) 147.

/27/ Irwin, D.J.G. and Livingston, A.E., Can. J. Phys. 54 (1976) 805.

/28/ Livingston, A.E., Kernahan, J.A., Irwin, D.J.G. and Pinnington, J., J. Phys. B 9 (1976) 389.

129/ McIntyre, L.C., Silver, J.D. and Jeley, N.A., in Beam-Foil Spectroscopy, Vol. 1, Atomic Structure and Lifetimes, Sellin, I.A. and Pegg, D.J. (eds.), Plenum Press, New York (1976) 331.

/30/ Havey, M.D., Balling, L.C. and Wright, J.J., J. Opt. Soc. Am. 67 (1977) 488.

/31/ Baudinet-Robinet, Y., Dumont, P.D., Garnir, H.P., Biémont, E. and Grevesse, N., J. Phys. Colloq. C1 (Paris) 40 (1979) 175.

/32/ Dumont, P.D., Garnir, H.P. and Baudinet-Robinet, Y., J. Opt. Soc. Am. 68 (1978) 825.

/33/ Dynefors, B.I. and Martinson, I., Phys. Scr. 17 (1978) 123.

/3t/ Kelly, F.M. and Mathur, M.S., Can. J. Phys. 56 (1978) 1422.

/35/ Kernahan, J.A., Pinnington, E.H., O’Neill, J.A., Brooks, R.L. and Donnelly, K.E., Phys. Scr. 19 (1979) 267.

/36/ Bashkin, S., Astner, G., Mannervik, S., Ramanujam, P.S., Scofield, M., Huldt, S. and Martinson, I., Phys. Scr. 21 (1980) 820.

/37/ Kwiatkowski, M., Teppner, U. and Zimmermann, Z. Phys. A 294 (1980) 109.

/38/ Liljeby, L., Lindgărd; A., Mannervik, S., Veje, E. and Jelenkovi, B., Phys. Scr. 21 (1980) 805.

/39/ Livingston, A.E., Pinnington, E.H., Irwin, D.J.G., Kernahan, J.A. and Brooks., R.L., J. Opt. Soc. Am. 71 (1981) 442.

/40/ Buchet-Poulizac, M.C., Buchet, J.P. and Ceyzeriat, P., Nucl. Instr. Meth., 202 (1982) 13. 
/41/ Chantepie, M., Cojan, J.L., Landais, J., Laniepce, B. and Moudden, A., Opt. Commun. 51 (1984) 396.

/42/ Jönsson, G., Kröll, S., Persson, A. and Sranberg, S., Phys. Rev. A 30 (1984) 2429.

/43/ Reistad, N., Jupén, C., Huldt, S., Engström, L. and Martinson, I., Phys. Scr. 32 (1985) 164.

/44/ Reistad, N., Engström, L. and Berry, H.G., Phys. Scr. 34 (1986) 158.

/45/ Berry, H.G., Shectman, R.M., Martinson, I., Bickel, W.S. and Bashkin, S., J. Opt. Soc. Am. 60 (1970) 335.

/46/ Livingston, A.E., Baudinet-Robinet, Y., Garnir, H.P. and Dumont, P.D., J. Opt. Soc. Am. 66 (1976) 1393.

Table 1. Comparison of theoretical and experimental radiative lifetimes ( $\mathrm{ns}$ ) for ions of the Mg sequence

\begin{tabular}{|c|c|c|c|c|c|}
\hline Z & STATE & PRES & $\mathrm{MCHF}$ & MS & EXPERIMENT \\
\hline 12 & $3 s 4 s^{1} S$ & 46.7 & & 47.4 & $47 \pm 3^{a g}, 20^{a f}$ \\
\hline 12 & $3 s 5 s^{1} S$ & 108 & & 104 & $163 \pm 8^{i}, 2.0 \pm 1.0^{a c}, 100 \pm 5^{a g}, 102 \pm 5^{a f}$ \\
\hline 12 & $3 s 6 s^{1} S$ & 216 & & 205 & $201 \pm 4^{i}, 211 \pm 12^{a g}$ \\
\hline 12 & $3 s 7 s^{1} S$ & 386 & & 365 & $350 \pm 16^{\text {ag }}$ \\
\hline 12 & $3 s 8 s^{1} S$ & 625 & & 595 & $548 \pm 35^{a g}$ \\
\hline 12 & $3 s 9 s^{1} S$ & 946 & & 926 & $846 \pm 40^{a g}$ \\
\hline 12 & $3 s 4 s^{3} S$ & 9.42 & & 9.7 & $13 \pm 1^{f}, 14.8 \pm 0.7^{i}, 10.1 \pm 0.8^{k}, 9.7 \pm 0.5^{u}, 9.7 \pm 0.6^{a b}$ \\
\hline 12 & $3 s 5 s^{3} S$ & 26.1 & & 26.5 & $25.6 \pm 2.1^{i}, 6.1 \pm 1.0^{a c}$ \\
\hline 12 & $3 s 6 s^{3} S$ & 56.2 & & 56.3 & $52.1 \pm 6^{i}, 51.8 \pm 3^{a b}$ \\
\hline 12 & $3 s 3 p^{1} P^{0}$ & 2.04 & 2.15 & 2.17 & $\begin{array}{l}1.99 \pm 0.08^{a}, 2.03 \pm 0.06^{b}, 2.01 \pm 0.06^{c}, 1.5 \pm 0.2^{f}, 2.2 \pm 0.2^{e} \\
1.9 \pm 0.3^{j}, 2.09 \pm 0.1^{0}, 2.00 \pm 0.04^{y}, 2.0 \pm 0.1^{a c}\end{array}$ \\
\hline 12 & $3 s 4 p^{1} p^{0}$ & 12.4 & & 14.3 & $10.4 \pm 2^{j}, 1.8 \pm 0.4^{a c}$ \\
\hline 12 & $3 s 5 p^{1} P^{0}$ & 42.8 & & 49.3 & $28 \pm 5^{j}$ \\
\hline 12 & $3 s 3 d^{1} D$ & 91.1 & 108.0 & 106 & $57.0 \pm 3.6^{i}, 81 \pm 6^{a g}, 72 \pm 4^{a f}$ \\
\hline 12 & $3 s+d^{1} D$ & 46.6 & & 42.3 & $54.9 \pm 1.4^{i}, 32 \pm 3^{k}, 57 \pm 3^{a g}, 53 \pm 3^{a f}$ \\
\hline 12 & $3 s 5 d^{1} D$ & 41.5 & & 37.9 & $44.3 \pm 2.4^{i}, 24 \pm 5^{a c}, 50 \pm 4^{a g}$ \\
\hline 12 & $3 s 6 d^{1} \mathrm{D}$ & 52.4 & & 47.6 & $50.3 \pm 2.2^{i}, 4.2 \pm 0.8^{a c}, 54 \pm 3^{a g}$ \\
\hline 12 & $3 s 7 d{ }^{1} \mathrm{D}$ & 71.1 & & 64.6 & $73.1 \pm 2.7^{i}, 92.6^{m}, 70 \pm 6^{a g}$ \\
\hline 12 & $3 s 8 d^{1} \mathrm{D}$ & 97.4 & & 90.4 & $85.4 \pm 10.5^{i}, 232^{m}, 93 \pm 7^{a g}$ \\
\hline 12 & $3 s 9 d^{1} \mathrm{D}$ & 132 & & 123 & $99.4 \pm 9.4^{i}, 127 \pm 8^{a g}$ \\
\hline 12 & $3 s 3 d^{3} \mathrm{D}$ & 5.68 & & 5.8 & $3.7 \pm 1^{f}, 6.6 \pm 0.5^{e}, 11.3 \pm 0.8^{i}, 6.5 \pm 0.5^{o}, 6.6 \pm 0.5^{k}, 5.9 \pm 0.4^{a b}$ \\
\hline 12 & $3 s 4 d^{3} D$ & 16.1 & & 15.9 & $10 \pm 1^{f}, 13.5 \pm 0.5^{e}, 18.4 \pm 0.7^{i}, 13.5 \pm 1^{k}, 15.6 \pm 0.9^{a b}$ \\
\hline 12 & $3 s 5 d^{3} D$ & 32.2 & & 33.4 & $34.1 \pm 1.5^{a b}$ \\
\hline 12 & $3 s 6 d^{3} D$ & 58.3 & & 59.9 & $55.7 \pm 3^{a b}, 2.7 \pm 0.4^{a c}$ \\
\hline 12 & $3 s 7 d^{3} D$ & 95.2 & & 98.1 & $91.5 \pm 5^{a b}$ \\
\hline 12 & $3 p^{2}{ }^{3} P$ & 1.76 & & 1.89 & $2.3 \pm 0.2^{f}, 2.2 \pm 0.2^{e}, 2.10 \pm 0.15^{\circ}$ \\
\hline 13 & $3 p^{2}{ }^{1} S$ & 0.91 & 0.97 & & \\
\hline 13 & $3 s 4 s^{1} S$ & 2.85 & & & $5.9 \pm 0.3^{d}$ \\
\hline 13 & $3 s+s^{3} S$ & 1.3 & & & $2: 1 \pm 0.2^{f}$ \\
\hline 13 & $3 s 3 p^{1} P^{0}$ & 0.66 & 0.70 & & $1.03 \pm 0.05^{v}, 0.65 \pm 0.10^{f}, 0.68 \pm 0.1^{q}, 0.72 \pm 0.11^{z}$ \\
\hline 13 & $3 p^{2} 3 P$ & 0.73 & & & $0.89 \pm 0.04^{z}, 0.5 \pm 0.1^{f}, 0.98 \pm 0.06^{v}$ \\
\hline 13 & $3 p^{2}{ }^{1} D$ & 7469 & 2381 & & \\
\hline 13 & $3 s 3 d^{1} D$ & 0.73 & 0.75 & & $0.71 \pm 0.03^{z}, 1.9 \pm 0.3^{d}$ \\
\hline 13 & $3 s+d^{1} D$ & 1.31 & & & $1.9 \pm 0.3^{d}$ \\
\hline 13 & $3 p 3 d^{1} \cdot D^{0}$ & 0.77 & 0.81 & & \\
\hline 13 & $3 s 3 d{ }^{3} D$ & 0.81 & & & $0.94 \pm 0.04^{v}, 0.77 \pm 0.10^{f}, 0.86 \pm 0.05^{z}$ \\
\hline 13 & $3 s+f^{3} F^{0}$ & 4.24 & & & $6.4 \pm 0.5^{g}, 4.8 \pm 0.6^{d}$ \\
\hline 13 & $3 s 5 f^{3} F^{0}$ & 14.5 & & & $14 \pm 2^{g}$ \\
\hline 13 & $3 s 6 f^{3} F^{0}$ & 16.7 & & & $15 \pm 1^{g}$ \\
\hline 13 & $3 s 7 f^{3} F^{0}$ & 5.05 & & & $5.0 \pm 0.5^{g}$ \\
\hline 14 & $3 p^{2} 1 S$ & 0.36 & 0.40 & & $0.58 \pm 0.04^{s}$ \\
\hline 14 & $3 s 4 s^{3} S$ & 0.41 & & & $1.06 \pm 0.05^{h}, 0.5 \pm 0.1^{a k}$ \\
\hline 14 & $3 s 3 p^{1} p^{0}$ & 0.38 & 0.39 & & $0.40 \pm 0.1^{h}, 0.41 \pm 0.09^{t}$ \\
\hline 14 & $3 p 3 d^{1} P^{0}$ & 2.15 & 0.51 & & 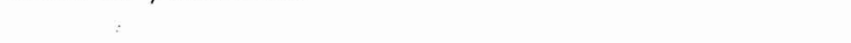 \\
\hline 14 & $3 s 6 p^{1} P^{0}$ & 0.25 & 0.71 & & \\
\hline 14 & $3 s 4 p^{3} P^{0}$ & 3.35 & & & $4.3 \pm 0.5^{h}, 3.4 \pm 0.3^{a a}$ \\
\hline $1 \pm$ & $3 p^{2}{ }^{1} D$ & 39.6 & 39.5 & & $26 \pm 3^{h}, 26.0 \pm 1.5^{a a}$ \\
\hline 14 & $3 s 3 d^{1} D$ & 0.21 & 0.22 & & \\
\hline 14 & $3 s+d^{1} D$ & 1.18 & & & $1.9 \pm 0.3^{h}, 1.25 \pm 0.15^{a a}$ \\
\hline 14 & $3 p 3 d^{1} D^{0}$ & 0.40 & 0.41 & & \\
\hline 14 & $3 s 3 d^{3} D$ & 0.34 & & & $0.36 \pm 0.04^{h}$ \\
\hline 14 & $3 s \pm d d^{3} D$ & 2.82 & & & $4.0 \pm 0.4^{h}, 3.3 \pm 0.3^{a a}$ \\
\hline
\end{tabular}


Table 1. Continued

\begin{tabular}{|c|c|c|c|c|c|}
\hline $\mathrm{Z}$ & STATE & PRES & $\mathrm{MCHF}$ & MS & EXPERIMENT \\
\hline 14 & $3 p 3 d^{1} F^{0}$ & 0.41 & 0.42 & & \\
\hline 14 & $3 s 5 f^{1} F^{0}$ & 0.48 & 0.50 & & \\
\hline 14 & $3 s 4 f^{3} F^{0}$ & 0.47 & & & $1.2 \pm 0.1^{h}$ \\
\hline 14 & $3 s 5 f^{3} F^{0}$ & 0.94 & & & $1.4 \pm 0.2^{h}$ \\
\hline 14 & $3 s 5 g{ }^{1} G$ & 2.77 & & & $4.1 \pm 0.4^{h}$ \\
\hline 14 & $3 s 5 g^{3} G$ & 2.76 & & & $4.3 \pm 0.5^{h}$ \\
\hline 16 & $3 p^{2}{ }^{1} S$ & 0.23 & 0.24 & & $0.18 \pm 0.04^{a h}$ \\
\hline 16 & $3 d^{2}{ }^{1} S$ & 0.086 & 0.098 & & \\
\hline 16 & $3 s 3 p^{1} p^{0}$ & 0.19 & 0.20 & & $0.28 \pm 0.01^{w}, 0.26 \pm 0.05^{a h}, 1.14 \pm 0.1^{a j}, 0.263 \pm 0.018^{r}$ \\
\hline 16 & $3 p 3 d^{1} p^{0}$ & 0.11 & 0.12 & & \\
\hline 16 & $3 s 4 p^{3} P^{0}$ & 0.66 & & & $0.79 \pm 0.05^{w}$ \\
\hline 16 & $3 p^{2} 1 D$ & 5.85 & 5.9 & & $5.0 \pm 0.4^{a h}, 5.6 \pm 0.5^{x}, 6.47 \pm 0.2^{a j}$ \\
\hline 16 & $3 s 3 d^{1} D$ & 0.083 & 0.085 & & $0.098 \pm 0.01^{w}, 0.13 \pm 0.02^{r}, 0.12 \pm 0.03^{a h}$ \\
\hline 16 & $3 d^{2} 1 D$ & 0.10 & 0.11 & & \\
\hline 16 & $3 p 3 d^{1} D^{0}$ & 0.19 & 0.20 & & $0.27 \pm 0.01^{w}$ \\
\hline 16 & $3 s 3 d^{3} D$ & 0.15 & & & $0.20 \pm 0.01^{w}, 0.17^{r}$ \\
\hline 16 & $3 p 3 d^{1} F^{0}$ & 0.087 & 0.087 & & \\
\hline 16 & $3 s 4 f^{3} F^{0}$ & 0.077 & & & $0.10 \pm 0.02^{a k}$ \\
\hline 16 & $3 s 7 g^{1} G$ & 0.14 & 0.17 & & \\
\hline 16 & $3 d^{2}{ }^{1} G$ & 0.34 & 0.35 & & \\
\hline 18 & $3 p^{2}{ }^{1} S$ & 0.15 & 0.15 & & $0.165 \pm 0.015^{a i}$ \\
\hline 18 & $3 d^{2} I S$ & 0.041 & 0.044 & & \\
\hline 18 & $3 s 4 s^{3} S$ & 0.034 & & & $0.030 \pm 0.005^{p}$ \\
\hline 18 & $3 s 3 p^{1} P^{0}$ & 0.13 & 0.13 & & $\begin{array}{l}0.181 \pm 0.011^{l}, 0.132 \pm 0.005^{a i}, 0.144 \pm 0.015^{a e}, 0.18 \pm 0.02^{a d} \\
0.184 \pm 0.009^{n}\end{array}$ \\
\hline 18 & $3 p 3 d^{1} P^{0}$ & 0.062 & 0.061 & & \\
\hline 18 & $3 s 4 p^{1} P^{0}$ & 0.052 & & & $0.036 \pm 0.005^{p}$ \\
\hline 18 & $3 p^{2}{ }^{1} D$ & 2.52 & 2.5 & & $1.85 \pm 0.10^{a i}, 1.720 \pm 0.150^{a e}$ \\
\hline 18 & $3 s 3 d^{1} D$ & 0.055 & 0.056 & & $0.050 \pm 0.010^{a i}, 0.083 \pm 0.010^{a e}, 0.08 \pm 0.02^{a d}$ \\
\hline 18 & $3 d^{2}{ }^{1} \mathrm{D}$ & 0.051 & 0.053 & & \\
\hline 18 & $3 p 3 d^{1} D^{0}$ & 0.13 & 0.13 & & \\
\hline 18 & $3 s 3 d^{3} D$ & 0.098 & & & $0.71 \pm 0.24^{l}, 0.120 \pm 0.015^{p}$ \\
\hline 18 & $3 s 4 d^{3} \mathrm{D}$ & 0.076 & & & $0.072 \pm 0.008^{p}$ \\
\hline 18 & $3 p 3 d^{1} F^{0}$ & 0.053 & 0.053 & & \\
\hline 18 & $3 s 4 f^{3} F^{0}$ & 0.022 & & & $0.049 \pm 0.005^{p}$ \\
\hline 18 & $3 d^{2}{ }^{1} G$ & 0.17 & 0.17 & & \\
\hline 20 & $3 p^{2}{ }^{1} S$ & 0.11 & 0.11 & & \\
\hline 20 & $3 d^{2}{ }^{1} S$ & 0.031 & 0.033 & & \\
\hline 20 & $3 s 3 p^{1} P^{0}$ & 0.092 & 0.093 & & \\
\hline 20 & $3 p 3 d^{1} P^{0}$ & 0.047 & 0.047 & & \\
\hline 20 & $3 p^{2}{ }^{1} D$ & 1.47 & 1.5 & & \\
\hline 20 & $3 s 3 d^{1} D$ & 0.042 & 0.042 & & \\
\hline 20 & $3 d^{2}{ }^{1} \mathrm{D}$ & 0.039 & 0.039 & & \\
\hline 20 & $3 p 3 d^{1} D^{0}$ & 0.094 & 0.095 & & \\
\hline 20 & $3 p 3 d^{1} F^{0}$ & 0.040 & 0.040 & & \\
\hline 20 & $3 d^{2}{ }^{1} G$ & 0.10 & 0.10 & & \\
\hline 26 & $3 p^{2}{ }^{1} S$ & 0.049 & 0.059 & & \\
\hline 26 & $3 d^{2}{ }^{1} S$ & 0.016 & 0.018 & & \\
\hline 26 & $3 s 3 p^{1} P^{0}$ & 0.043 & 0.051 & & \\
\hline 26 & $3 p 3^{1} d^{1} P^{0}$ & 0.025 & 0.028 & & \\
\hline 26 & $3 p^{2}{ }^{1} D$ & 0.50 & 0.60 & & \\
\hline 26 & $3 s 3 d^{1} D$ & 0.023 & 0.026 & & \\
\hline 26 & $3 d^{2}{ }^{1} D$ & 0.022 & 0.023 & & \\
\hline 26 & $3 p 3 d^{1} D^{0}$ & 0.049 & 0.055 & & \\
\hline 26 & $3 p 3 d^{1} F^{0}$ & 0.023 & 0.024 & & \\
\hline 26 & $3 d^{2}{ }^{1} G$ & 0.044 & 0.048 & & \\
\hline
\end{tabular}

Theory: PRES, present results; MCHF, Ref. 8; MS, Ref. 9.

Experiment: a, Ref. 10; b, Ref. 11; c, Ref. 12; d, Ref. 13; e, Ref. 14; f, Ref. 15; g, Ref. 16; h, Ref. 17; i, Ref. 18 ; j, Ref. 19; k, Ref. 20; l, Ref. 21; m, Ref. 22; n, Ref. 23; o, Ref. 24; p, Ref. 25; q, Ref. 26; r, Ref. 27; s, Ref. 28; t, Ref. 29; u, Ref. 30; v, Ref. 31; w, Ref. 32; x, Ref. 33; y, Ref. 34; $z$, Ref. 35; aa, Ref. 36; ab, Ref. 37; ac, Ref. 38; ad, Ref. 39; ae, Ref. 40; af, Ref. 41; ag, Ref. 42; ah, Ref. 43; ai, Ref. 44; aj, Ref. 45; ak, Ref. 46. 